\title{
Mestrado Profissional em Saúde Pública: do marco legal à experiência em uma instituição de pesquisa e ensino
}

\author{
Professional Master's in Public Health: from legal precepts \\ to experience in a research and education institution
}

${ }^{1}$ Escola Nacional de Saúde Pública, Fundação Oswaldo Cruz. Av. Leopoldo Bulhõe 1480/315, Manguinhos. 21.041-210 Rio de Janeiro RJ Brasil.

gidborges@ensp.fiocruz.br
Abstract This study is about the discourses that prevailed over the course of time in Brazilian legislation for the Master's Course in Public Health, and how a Brazilian research and education institution in the area of Public Health appropriated these discourses in the creation of its course proposals. Discourse analysis techniques were applied to legal documents and to sixteen master's programs developed in the institution under scrutiny. The results revealed that with respect to legislation, analysis of the historical timeline makes it possible to say that the initial lack of definition progressively gave rise to the understanding that the identity of such post-graduate education presupposes pedagogical practices that promote the strengthening of ties between academia and the workplace. And, in relation to the master's course proposals for public health in the institutions under scrutiny, they still operate with traditionally consolidated training schemes and tend to standardize their proposals with those of the academic model. It was assumed in this study that the series of proposals would clearly mirror the intentions and, above all, the vision of the training institutions in the area of public health on this stricto sensu model, the identity of which also appears poorly defined.

Key words Public health, Professional Master's degree, Curriculum, Legislation
Resumo Trata-se de um estudo sobre os discursos que vigoraram ao longo do tempo na legislação brasileira sobre Mestrado Profissional (MP), e como uma instituição de pesquisa e ensino na área da Saúde Pública se apropriou deles na construção de suas propostas de cursos. Técnicas de análise de discurso foram utilizadas nos documentos legais e cotejadas com dezesseis propostas de cursos de MP da instituição-caso. Os resultados mostram que em relação à legislação, a análise da linha histórica permite dizer que as indefinições iniciais vêm progressivamente dando lugar ao entendimento de que a identidade dessa modalidade de formação pressupõe práticas pedagógicas que promovam o estreitamento das relações entre a academia e o mundo do trabalho. E, em relação às propostas de cursos de MP da instituição-caso, elas ainda operam com esquemas de formação tradicionalmente consolidados e tendem a conformar suas propostas à semelhança daquelas da modalidade acadêmica. Assumiu-se no presente estudo que o conjunto das propostas expressariam suficientemente as intencionalidades e, sobretudo, a visão das instituições formadoras na área de saúde pública sobre essa modalidade stricto sensu e cuja identidade ainda parece pouco determinada.

Palavras-chave Saúde Pública, Mestrado profissional, Currículo, Legislação 


\section{Introdução}

Desde a instituição, em 1995, da modalidade de pós-graduação stricto sensu, denominada Mestrado Profissional (MP), e do o lançamento do "Programa de Flexibilização do Modelo de PósGraduação senso estrito em nível de Mestrado" pela Coordenadoria de Aperfeiçoamento de Pessoal de Nível Superior do Ministério da Educação - Capes $/ \mathrm{MEC}^{1}$, uma série de documentos legais foram publicados para explicitar e regulamentar seus fundamentos, objetivos e exigências ${ }^{2-6}$. Pode-se dizer que sua mais forte característica é a possibilidade de aproximar a pesquisa do exercício profissional. Ao valer-se dos recursos acadêmicos para melhor refletir e intervir no processo de trabalho, os egressos dos cursos de MP devem ser capazes de realizar investigação no seu ambiente profissional, com vistas à inovação $0^{5,6}$. Para começar, o termo "profissional" é utilizado somente no Brasil; os mestrados nos países europeus e na América do Norte que têm características semelhantes às mencionadas neste artigo recebem, na maioria das vezes, o nome da área de conhecimento em que o curso foi realizado ${ }^{7}$.

Caracterizar, de forma distintiva e minimamente precisa, os cursos dessa modalidade no contexto do sistema educacional brasileiro tem sido mote para o debate acadêmico e jurídico que se tem observado, desde a segunda metade da década de 1990, a respeito do que chamamos "identidade" do MP. Ainda que este seja um aspecto que distingue essa modalidade de outras de formação pós-graduada, interrogações a respeito da sua identidade persistem. O que o MP representa no contexto da pós-graduação brasileira? Que elementos ele guarda que o distingue do Mestrado Acadêmico (MA)? Que limites ele pretende romper que não foi possível fazê-lo pelo MA?

Para além do texto legal, a produção científica sobre o tema ainda é escassa no Brasil, e boa parte do que já foi divulgado, o foi em veículos institucionais, como a Revista Brasileira de Pósgraduação, publicada pela Capes, e que não oferecem respostas suficientes à essas questões. Negret $^{8}$, por exemplo, diz que:

Não obstante essa diversidade, a identidade dos mestrados profissionais não está somente determinada pela sua área temática, mas, fundamentalmente, pelo enorme desafio de integrar com rigor a pesquisa no seu processo de desenvolvimento e conseguir a aplicabilidade dos resultados para transformar a realidade estudada. Esse desafio, que significa o verdadeiro sentido da universidade, implica a inserção dos MP no seio da sociedade para realizar com eficiência e clareza os estudos e análises e, desse modo, alcançar a compreensão dos conflitos e problemas socioambientais no território nacional e propor soluções científicas e técnicas. [...] Dessa forma, a identidade dos MP consiste no consequente compromisso de obter conteúdos teórico-metodológicos capazes de dar conta das análises e estudos da vantajosa riqueza da biodiversidade do país, bem como em obter os meios, a legitimidade social e maior viabilidade para a sua aplicação. Trata-se então da construção de marcos conceituais analíticos em articulação com setores da sociedade para, dessa forma, criar os mecanismos da aplicabilidade dos resultados da pesquisa. É uma inserção dos mestrados na sociedade e, portanto, uma maior aproximação e articulação entre a universidade e a realidade social.

A busca por uma melhor compreensão sobre os sentidos e a utilidade da formação stricto sensu de caráter profissional no campo da Saúde Coletiva, tem motivado discussões, quer de caráter teórico que projetam novos cenários para a pós-graduação ${ }^{9}$, quer numa perspectiva de discutir os processos de avaliação dos cursos ${ }^{10,11}$, apresentar experiências em curso $^{12}$,ou analisar a identidade do mestrado profissional no campo da saúde pública ${ }^{13}$.

Os debates são realizados por instituições que tomaram a iniciativa de oferecer cursos de MP como uma oportunidade para a formação de quadros estratégicos e gestores para o Sistema Único de Saúde (SUS); e vão desde a problematização da pertinência de um mestrado inteiramente articulado com os cursos de especialização latu sensu, passando pela discussão do seu potencial de formar profissionais que utilizam ferramentas científicas para identificar e analisar problemas vivenciados no SUS e propor inovações no setor, até a discussão sobre os desafios da substituição gradativa da modalidade acadêmica pela profissional.

Frente a esses questionamentos, partiu-se do pressuposto de que investigar os fundamentos políticos, epistemológicos e pedagógicos que servem de apoio ao MP, e que fomentam a introdução de novos elementos formativos na pós-graduação, é uma preocupação relevante. Assumido este pressuposto, realizou-se um estudo de natureza qualitativa em duas dimensões: análise dos discursos que vigoraram na legislação brasileira sobre a modalidade de MP entre 1995 e 2009; e o modo como uma instituição de pesquisa e ensino no campo da Saúde Pública que oferece cursos de MP se apropriou desses discursos na construção de suas propostas. 
A escolha dessa instituição deveu-se à sua importância na formação de quadros profissionais para o SUS, ao fato de ser uma das instituições pioneiras na oferta de cursos de MP, às múltiplas demandas por cursos nessa modalidade que ela recebe de órgãos de governo e ao grande número de cursos de MP oferecidos no período do estudo. Entre 2002 e 2013, a instituição finalizou 21 turmas e titulou um total de 514 mestres profissionais; atualmente, são 11 turmas em andamento e um total de 204 alunos matriculados. E, finalmente, à necessidade de se refletir sobre os processos formativos no campo da saúde pública.

\section{Método}

A pesquisa, com abordagem qualitativa, de natureza documental, desenvolveu-se por meio de estudo de caso. Importante destacar que as desvantagens da análise documental em pesquisas qualitativas não dizem respeito ao método propriamente dito, mas sim às possibilidades de acesso ao documento e que este contenha todas as informações necessárias.

Assim, a fonte de dados constituiu-se do conjunto dos documentos que regulamentam o MP e de dezesseis propostas desse curso da institui- ção-caso. Todas as propostas de curso foram obtidas nos arquivos da coordenação do Programa de Pós-graduação, ou diretamente dos coordenadores. Toda legislação sobre o MP foi obtida no sitio internet da Capes e na Revista Brasileira de Pós-graduação. Esta pesquisa foi aprovada pelo CEP da instituição.

Fez-se uso da técnica de análise de discurso ${ }^{14}$. Foram observadas as seguintes etapas:

(a) leitura da legislação sobre MP publicada desde o lançamento do Programa de Flexibilização, em 1995. Por meio desta, foi possível reconstruir a linha histórica que permitiu uma análise comparativa das mudanças e permanências de sentido presentes nos textos legais. Concluída esta etapa, uma nova leitura foi realizada, com o propósito de identificar as categorias analíticas centrais, descritas no Quadro 1.

(b) codificação temática dos textos que resultou na análise morfológica e semântica dos discursos, nos modos pelos quais a linguagem foi empregada, as incoerências, imprecisões, alterações e indefinições presentes nos documentos legais. A análise faz referência às omissões e ao contexto nos quais os discursos foram produzidos. Nessa etapa, seguiu-se a orientação de Brandão ${ }^{15}$, para quem o conhecimento do contexto social em que os discursos são produzidos, faculta ao pesquisador reconhecer os significa-

Quadro 1. Categorias de Análise do Estudo.

\begin{tabular}{|l|l|}
\hline \multicolumn{1}{|c|}{ Categorias } & \multicolumn{1}{c|}{ Descrição } \\
\hline $\begin{array}{l}\text { Relação academia- } \\
\text { contexto profissional }\end{array}$ & $\begin{array}{l}\text { como a legislação e as propostas de curso preveem a articulação entre os } \\
\text { binômios "academia-serviço", "academia-trabalho" e "teoria-prática" }\end{array}$ \\
\hline Estrutura curricular & $\begin{array}{l}\text { modelo de proposta curricular adotado, considerando que o público-alvo tem } \\
\text { vínculo empregatício, ampla experiência profissional e sem disponibilidade para } \\
\text { se dedicar exclusivamente ao curso }\end{array}$ \\
\hline $\begin{array}{l}\text { Credenciamento } \\
\text { docente e do curso }\end{array}$ & $\begin{array}{l}\text { como a Capes define os critérios de credenciamento docente para orientação no } \\
\text { critérios da Capes para credenciamento dos cursos }\end{array}$ \\
\hline $\begin{array}{l}\text { Trabalho de } \\
\text { conclusão de curso }\end{array}$ & $\begin{array}{l}\text { se é prevista a apresentação de produto diversificado e coerente com o contexto } \\
\text { de trabalho do aluno; identificação da forma como a instituição-caso considera } \\
\text { esses critérios em suas propostas de curso }\end{array}$ \\
\hline Avaliação externa & $\begin{array}{l}\text { critérios utilizados pela Capes para avaliar o MP e sua relação com o MA e de que } \\
\text { forma a instituição-caso considera esses critérios em suas propostas de curso, } \\
\text { tanto na avaliação dos alunos quanto do programa de modo geral }\end{array}$ \\
\hline $\begin{array}{l}\text { Fontes de } \\
\text { financiamento }\end{array}$ & $\begin{array}{l}\text { o que a legislação da Capes prevê e como a instituição-caso se organiza para } \\
\text { atender às exigências legais }\end{array}$ \\
\hline
\end{tabular}


dos do que é dito e não dito em relação, entre outros, à posição ocupada por locutores e receptores no espaço social.

c) interpretação dos dados, relacionando os discursos da legislação com os discursos das propostas de curso. Analisou-se dezesseis propostas, aqui identificadas pelo código $\mathrm{P}$, seguido de numeração sequencial de 1 a 16, atribuída aleatoriamente aos documentos pesquisados. Ressalta-se que a análise limitou-se às propostas, sem avançar para o modo como elas foram implementadas.

\section{Resultados e discussão}

Os resultados são apresentados em duas dimensões. Na primeira, a partir das categorias analíticas centrais, elaborou-se a linha histórica da produção discursiva legal acerca do MP como modalidade de formação em pós-graduação. $\mathrm{O}$ Quadro 2 sintetiza essa linha histórica. $\mathrm{Na}$ sequência, expôs-se a apropriação desses discursos pela instituição-caso nas propostas de cursos para essa modalidade. Sua leitura permitiu identificar as variações observadas nos aspectos relativos a cada uma das categorias analíticas centrais durante o processo de caracterização do marco regulatório dessa modalidade.

\section{Relação Academia-Contexto Profissional}

Um dos aspectos comuns do marco regulatório que define o MP é que ele se realiza por meio de "parceria com o setor produtivo"1 e "intercâmbio com empresas e instituições governamentais e não governamentais" teresse comum entre setor acadêmico e um setor não acadêmico"'. Outro aspecto comum é de que os currículos nessa modalidade devem buscar a articulação entre conhecimento atualizado, metodologia pertinente e aplicação orientada para a prática profissional ${ }^{5,6}$.

$\mathrm{Na}$ instituição-caso, o uso frequente de frases genéricas, tais como "atender a necessidades do cotidiano" (P3), "necessidade de qualificar profissionais" (P11), "responder a demandas de formação" (P15), ao fazer referências à relação entre a academia e os contextos profissionais, sugere a ausência de um diagnóstico prévio das características específicas e dos contextos em que se inserem o público-alvo desses cursos. Isso pode significar que a aproximação entre academia e serviço não se apoia em dados sobre o perfil dos candidatos e das instituições demandantes de cursos. Uma das propostas (P9) é exceção, pois apresenta um diagnóstico, ainda que sem explicitar a fonte. "O Curso se dá em função da identificação de alguns problemas: baixo controle sobre o crescente número de tecnologias; dificuldades para elaboração, utilização e implementação de avaliação de tecnologias em saúde; falha no desenho de mecanismos regulatórios, na delimitação de critérios e no desenvolvimento de normas e instrumentos [...]; incipiência das atividades de acompanhamento e avaliação tecnológicas em saúde; poucos profissionais do SUS capacitados" (P9).

Não se tem como determinar todos os elementos envolvidos na formação humana, contudo, na ausência de um diagnóstico das necessidades institucionais e dos sujeitos que se movimentam em busca de formação stricto sensu, em que bases se apoiaria a parceria entre o MP e o serviço?

No que concerne ao modo de construção dos currículos, que, de acordo com a linha histórica do marco legal, deveria se concretizar por meio do diálogo entre a academia e o mundo do trabalho, observa-se que, em três das propostas, o modelo pedagógico levou em consideração as discussões com os demandantes do curso: realização de uma oficina para "fornecer subsídios técnico e político-estratégicos para o desenho de um curso de MP..." (P5); estruturação de um currículo integrado $[\ldots .$.$] entre ensino-comunidade-$ trabalho (P7); "valorizar o papel e a experiência profissional do aprendiz" (P13).

Apesar de não se explicitarem os conteúdos dessas discussões e como elas contribuíram com o desenho da estrutura curricular, as propostas podem refletir um esforço de aproximação aos contextos profissionais a que se destinavam, na tentativa de produzir de forma compartilhada os conhecimentos a serem utilizados nos processos de trabalho.

É possível identificar nessas propostas três estratégias de integração. A primeira delas por meio das dissertações, já que "o tema da dissertação deverá obrigatoriamente versar sobre assuntos relacionados à necessidade do serviço" (P1); a segunda pela prática de "estágios nacionais e internacionais" (P7); a terceira mediante a realização de oficinas de trabalho em conjunto para identificar demandas e estruturar conteúdos necessários àquela formação: "foram realizadas três oficinas de consenso visando adequar a proposta às necessidades definidas pela Secretaria de Saúde" (P9); "a definição de demandas e necessidades percebidas junto aos alunos e insti- 
Quadro 2. Principais características das Portarias e documentos divulgados pela Capes sobre o Mestrado Profissional.

\begin{tabular}{|c|c|c|c|}
\hline $\begin{array}{l}\text { Portarias e } \\
\text { documentos }\end{array}$ & $\begin{array}{l}\text { Relação academia- } \\
\text { contexto profissional }\end{array}$ & Estrutura curricular & Credenciamento docente e do curso \\
\hline $\begin{array}{l}\text { Portaria no } \\
47(1995)^{1}\end{array}$ & $\begin{array}{l}\text { Articular as atividades de } \\
\text { ensino com as aplicações de } \\
\text { pesquisas, em termos } \\
\text { coerentes com seu objetivo, } \\
\text { de forma diferenciada e } \\
\text { flexível. A existência de } \\
\text { projetos em parceria com o } \\
\text { setor produtivo. }\end{array}$ & $\begin{array}{l}\text { Deve ser clara e } \\
\text { consistentemente vinculada à } \\
\text { especificidade do curso e ser } \\
\text { compatível com um tempo de } \\
\text { titulação mínimo de um ano. }\end{array}$ & $\begin{array}{l}\text { Devem ser doutores ou de formação } \\
\text { profissional inquestionável; a } \\
\text { recomendação de cursos, de início, } \\
\text { limitar-se-á a projetos oriundos de } \\
\text { instituições que já possuam curso(s) de } \\
\text { pós-graduação com conceito A ou B. }\end{array}$ \\
\hline $\begin{array}{l}\text { Portaria no } \\
80(1998)^{2}\end{array}$ & $\begin{array}{l}\text { Currículo deve articular } \\
\text { ensino com aplicação } \\
\text { profissional. }\end{array}$ & $\begin{array}{l}\text { Oferecer condições de trabalho e } \\
\text { de carga horária docente } \\
\text { compatível com as necessidades } \\
\text { do curso, admitindo o regime de } \\
\text { dedicação parcial. } \\
\text { Tempo mínimo para a conclusão } \\
\text { do curso é de um ano }\end{array}$ & $\begin{array}{l}\text { Quadro docente integrado } \\
\text { predominantemente por doutores [...] } \\
\text { podendo uma parcela desse quadro ser } \\
\text { constituído por profissionais } \\
\text { qualificados. As instituições... [que] } \\
\text { revelem claramente qualificação } \\
\text { científica, tecnológica e/ou artística } \\
\text { presumem-se qualificadas }\end{array}$ \\
\hline $\begin{array}{l}\text { Documento } \\
\text { no }^{\circ} 02(1999)\end{array}$ & $\begin{array}{l}\text { Interesse comum entre } \\
\text { setor acadêmico e não } \\
\text { acadêmico. }\end{array}$ & $\begin{array}{l}\text { Articular conhecimento básico, } \\
\text { domínio de metodologia } \\
\text { cientifica e aplicação profissional } \\
\text { (conciliando disciplinas que } \\
\text { garantam formação sólida com } \\
\text { disciplinas práticas). Dois anos } \\
\text { como tempo máximo para a } \\
\text { conclusão do curso. }\end{array}$ & $\begin{array}{l}\text { Composto predominantemente por } \\
\text { doutores, mas poderá incluir uma } \\
\text { parcela de profissionais não doutores; } \\
\text { preferencialmente programas } \\
\text { credenciados pela Capes e que } \\
\text { desenvolvam atividades de extensão ou } \\
\text { prestação de serviços no campo. }\end{array}$ \\
\hline $\begin{array}{l}\text { Parâmetros } \\
\text { para } \\
\text { Avaliação } \\
(2002)\end{array}$ & $\begin{array}{l}\text { Intercâmbio com empresas } \\
\text { e instituições } \\
\text { governamentais e não } \\
\text { governamentais. }\end{array}$ & $\begin{array}{l}\text { Apresentar o projeto pedagógico } \\
\text { ajustado aos objetivos específicos } \\
\text { do curso e ao desenvolvimento } \\
\text { do curso e estabelece } 36 \text { meses } \\
\text { como prazo máximo de } \\
\text { conclusão do curso. }\end{array}$ & $\begin{array}{l}\text { Corpo docente constituído } \\
\text { predominantemente por doutores (no } \\
\text { mínimo o dobro dos especialistas sem } \\
\text { doutoramento), devendo incluir } \\
\text { profissionais com qualificação. }\end{array}$ \\
\hline 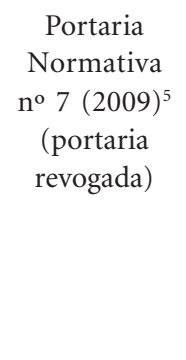 & $\begin{array}{l}\text { Articulação entre } \\
\text { conhecimento atualizado, } \\
\text { metodologia pertinente e } \\
\text { aplicação orientada para a } \\
\text { prática profissional [...] } \\
\text { visando atender demandas } \\
\text { sociais, organizacionais ou } \\
\text { profissionais e do mercado } \\
\text { de trabalho. }\end{array}$ & $\begin{array}{l}\text { Inclusão de áreas correlatas como } \\
\text { "legislação, comunicação, } \\
\text { administração e gestão, ciência } \\
\text { política e ética". } \\
\text { Ser compatível com um tempo } \\
\text { de titulação mínimo de um ano } \\
\text { e no máximo de dois anos. }\end{array}$ & $\begin{array}{l}\text { Apresentar, de forma equilibrada, } \\
\text { corpo docente integrado por doutores, } \\
\text { profissionais e técnicos com } \\
\text { experiência em pesquisa aplicada ao } \\
\text { desenvolvimento e à inovação. }\end{array}$ \\
\hline $\begin{array}{c}\text { Portaria } \\
\text { Normativa } \\
\mathrm{n}^{\circ} 17(2009)^{6}\end{array}$ & $\begin{array}{l}\text { O mesmo da Portaria } \\
\text { Normativa no } 7 \text { de } 2009^{5}\end{array}$ & $\begin{array}{l}\text { Exclusão do tempo mínimo e } \\
\text { máximo de duração do curso. }\end{array}$ & $\begin{array}{l}\text { O mesmo da Portaria Normativa no } 7 \\
\text { de } 2009^{5}\end{array}$ \\
\hline
\end{tabular}

tuições envolvidas, bem como a sua adequação à grade curricular do demandante, é feita por meio de oficinas de trabalho previamente ao início das atividades regulares do curso" (P15). 


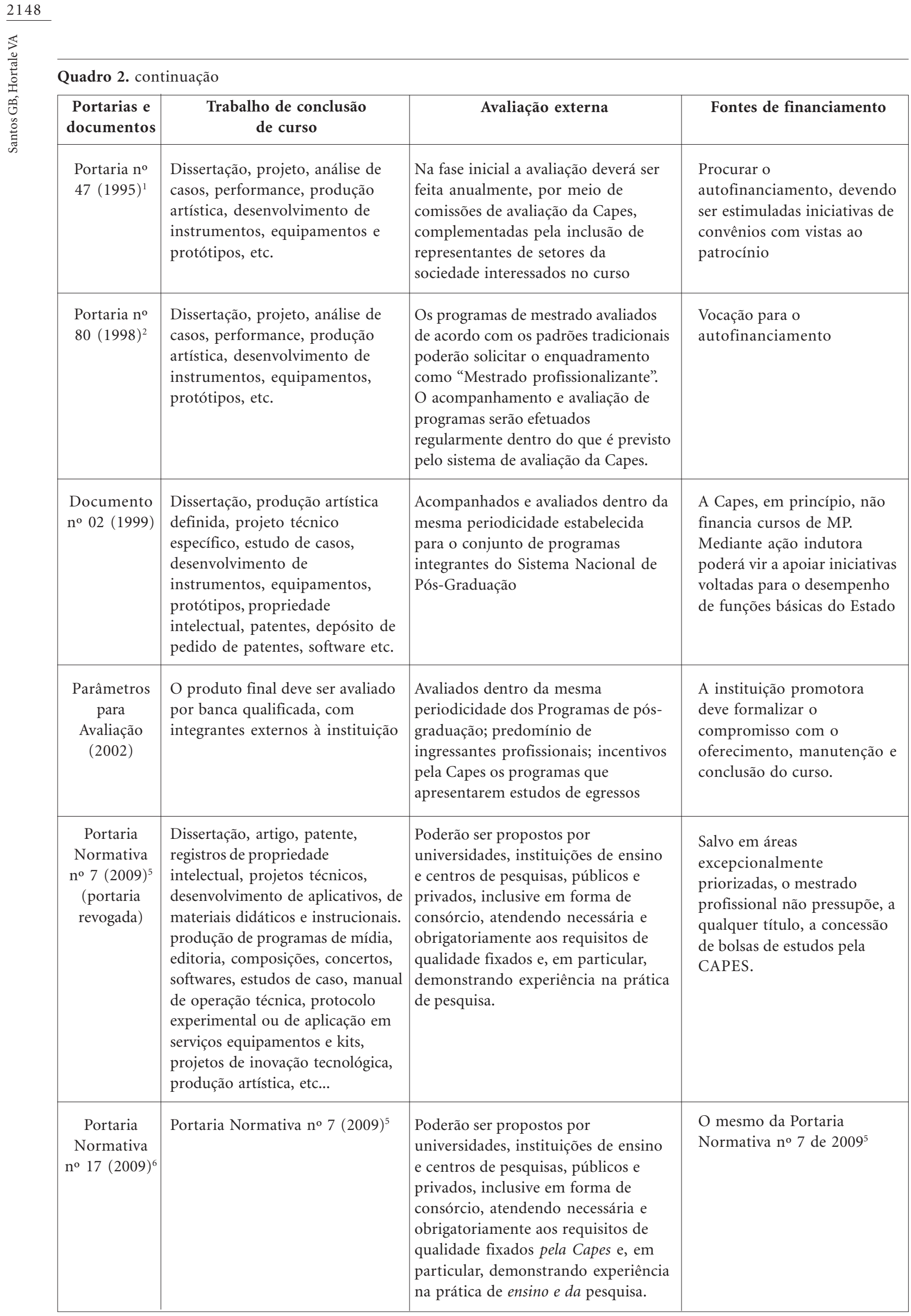

Observação: A Portaria Normativa no 17 revoga ainda o artigo $2^{\circ}$ da portaria no $07 / 09$ que diz: "O titulo de mestre obtido nos cursos de mestrado profissional reconhecidos e avaliados pela Capes e credenciados pelo conselho Nacional de Educação - CNE tem validade nacional e outorga ao seu detentor os mesmos direitos concedidos aos portadores da titulação nos cursos de mestrado acadêmico". Sendo este, substituído por: "O titulo de mestre obtido nos cursos de mestrado profissional reconhecidos e avaliados pela Capes e credenciados pelo Conselho Nacional de Educação - CNE tem validade nacional". 


\section{Estrutura curricular}

A Portaria de $1998^{2}$ se dedica a aspectos operacionais, como oferecer condições de trabalho e de carga horária docente compatível com as necessidades do curso, admitindo o regime de dedicação parcial. Já as Portarias de $2009^{5,6}$ definem quer os aspectos pedagógicos, quer a aplicabilidade técnica do currículo, a flexibilidade operacional e a organização do conhecimento técnico-científico.

Quanto à definição do tempos mínimo e máximo de finalização do MP, a norma variou ao longo do tempo: a Portaria de $1998^{2}$ estabelece o mínimo de um ano para a conclusão do curso; nos Parâmetros para Avaliação de $1999^{3}$ são estabelecidos dois anos como tempo máximo para a conclusão do curso e os Parâmetros para $2002^{4}$ definem 36 meses como prazo máximo.

O MP, criado para atender a demandas específicas, exigiria uma organização curricular específica, "articulando o ensino com a aplicação profissional, de forma diferenciada e flexível", "que garantam uma formação básica sólida com disciplinas e práticas voltadas para o conhecimento e utilização das tecnologias mais recentes e inovadoras, relativas ao campo de atuação profissional focalizado" 4

Seria diferente se o profissional ingressasse na modalidade acadêmica para estudar sobre um tema específico de sua atividade e do interesse da instituição a qual pertence e, principalmente, se estivesse liberado para isso? Dito de outra forma: Se a proposta pedagógica do MP não for diferenciada do MA, e se não houver interesse da instituição que indicou o profissional para os produtos advindos dessa formação, o que diferenciaria uma modalidade da outra? Esperar-seia que as propostas de cursos de MP pudessem atribuir significados e sentidos a essa normativa. O que se apresenta a seguir desmente essa possibilidade.

No que diz respeito à estrutura curricular das propostas, chama a atenção a variedade de modelos pedagógicos, sem qualquer justificativa sobre as razões que levaram seus idealizadores a adotarem tal modelo. Predomina a estrutura modular, em um formato interdisciplinar com a realização de estágios (P7, P10, P14, P15, P18); algumas propostas também fazem referência superficial aos modelos de "currículo integrado" (P7) e de "unidades de aprendizagem" (P4 e P5).

Em todas as propostas está presente a preocupação com a relação "academia-serviço": a P11 apresenta um desenho curricular organizado por blocos, denominados "teórico-contextual", "gerencial" e "aplicado"; a P13 organiza-se em módulos "teórico", "teórico-metodológico" e "prático"; e a P6 previu a "realização de uma oficina para fornecer subsídios técnicos e político-estratégicos para o desenho de um curso MP”. No entanto essas propostas consideraram na sua construção perspectivas epistemológicas diferenciadas sobre a relação "teoria-prática", ou seja; na primeira, a teoria e a prática podem ser vistas como interdependentes, e a construção do currículo seria o elemento de integração; na segunda, a prática é entendida como um processo decorrente da teoria; e na terceira, a investigação sobre a prática, concretizada em uma oficina de trabalho, é entendida como a busca "científica" por elementos dessa prática para construir o currículo. Em resumo, apesar de o tema da relação "teoria-prática" aparecer de forma recorrente, tanto no texto da legislação quanto no das propostas de curso, ainda o fazem de forma insuficiente para se perceber qual seria a identidade do MP, porque não se explicitam os modos dessa relação.

$\mathrm{Na}$ distribuição da carga horária e da organização curricular, identificam-se aspectos divergentes. O que mais se destaca é a grande variação na carga horária total (de 1040 horas em P7 a 1660 horas em P10). Além disso, também chama a atenção as diferenças entre a carga horária destinada a atividades teóricas, práticas, atividades de dispersão (aparecem em 4 propostas), pesquisa operacional e elaboração de dissertação. Também importantes são as propostas que utilizam outros termos (P11 e P12 usam os termos teórico-prático, gerencial e aplicado), e as que não distinguem disciplinas teóricas e práticas, ou ainda, não evidenciam preocupação dessa ordem (P4, P5, P6, P8, P9 e P12).

Observa-se um desequilíbrio entre as atividades denominadas teóricas e práticas. Algumas propostas incluem maior carga horária para as atividades teóricas do que para as práticas, exceto a P13, em que ocorre o inverso, e a P7, em que é igual para ambas. Pode-se supor que as atividades de feição teórica predominam na relação teoria-prática.

\section{Credenciamento docente e do curso}

Para o credenciamento docente, também existem, ao longo do tempo, variações de ênfase quanto à sua titulação. A Portaria de $1995^{1}$ diz que eles "devem ser doutores ou de formação profissional inquestionável"; a de $1998^{2}$, artigo 2ª que o "quadro docente integrado predominantemente por 
doutores [...] podendo uma parcela desse quadro ser constituído por profissionais qualificados". Já no Parâmetros para Avaliação do MP de $1999^{3}$, o curso é "composto predominantemente por doutores, mas poderá incluir uma parcela de profissionais não doutores", e no Parâmetros para Avaliação de 20024 " "o corpo docente para um MP deverá: a) ser constituído predominantemente por doutores (no mínimo o dobro dos especialistas sem doutoramento) devendo incluir profissionais com qualificação" [grifos nossos]

A redação dos textos é vaga quanto à participação de doutores e de profissionais sem doutorado, pois fazem uso de marcadores semânticos com significados diversos. A Portaria de $1998^{2}$ dá a entender que o corpo docente deve ser predominantemente de doutores, e a inclusão de profissionais qualificados seria opcional; diferente, portanto, dos Parâmetros para Avaliação que considera a presença de profissionais qualificados como uma obrigatoriedade. Se o termo qualificação profissional inquestionável não tem um significado objetivo, o uso de adjetivos dessa natureza pode criar interpretações ambíguas e subjetivas. Pode-se supor que os Parâmetros para Avaliação de $1999^{3}$, ao substituir o termo "inquestionável" por "comprovado", tenha dado mais objetividade ao artigo da lei; porém, seria necessário ponderar se houve alguma intenção do legislador ao usar estes termos, motivado pela dificuldade em estabelecer parâmetros capazes de atender aos mais diversos campos profissionais.

É incontestável que a legislação sobre o MP trouxe uma nova perspectiva de articulação entre a academia e o mundo do trabalho, no entanto a hegemonia do modelo acadêmico ainda prevalece. Quando a Portaria de $1995^{1}$ define que profissionais com ampla experiência "deverão constituir uma parcela restrita", e a de $1998^{2}$, assim como os documentos de $1999^{3}$ e de $2002^{4}$, declara que o "quadro docente [deve ser] integrado predominantemente por doutores", entende-se que o uso do advérbio "predominantemente" poderia significar o interesse em se preservar as características ditas "acadêmicas" no MP e, ao mesmo tempo, deixar em segundo plano os saberes advindos da experiência.

Se a Portaria de $2009^{5}$ considera a existência de uma "forma equilibrada do número de doutores e dos demais profissionais", e a Portaria de $1998^{2}$, a de ser "predominantemente de doutores", permaneceria a imprecisão, mesmo com a redução do peso "academicista". Desse ponto de vista, a Portaria $2009^{5}$ deixa a cargo do próprio curso a decisão sobre esse quantitativo, ainda que, de forma imprecisa, a normativa anterior já o tivesse feito.

Pode-se concluir que, baseado nesse critério, o peso da relevância acadêmica e da experiência na construção da identidade do MP não são explicitados. Nesse caso, eleger os critérios acadêmicos como mais efetivos, quiçá únicos, de credenciamento docente para o MP, não significaria a exclusão de profissionais com experiência reconhecida?

Ao interpretar que o MP tem por objetivo instituir um programa de formação com pesquisas voltadas para os serviços e à produção de tecnologia por segmentos não acadêmicos, observa-se que os Parâmetros para Avaliação de $1999^{3}$ consideram que o propósito do MP não é o de formar pesquisadores e sim qualificar profissionais para atuar nos serviços. Paradoxalmente, o próprio documento ao enfatizar que o MP e o MA, têm padrões de qualidade equivalentes, gera ambiguidades na sua interpretação. Se o MP tem como objetivo a qualificação de profissionais para fazer da pesquisa cientifica um instrumento voltado para a inovação do seu processo de trabalho, não pareceria incoerente esses profissionais, uma vez mestres, tornarem-se docentes universitários, ainda que no MP não se tenha previsto esse tipo de formação?

Quanto ao credenciamento das instituições para oferecer cursos de MP, os textos da legislação se tornaram mais flexíveis ao longo dos anos. Se a Portaria de $1995^{1}$ (não mais em vigor), a mais exigente delas, diz que "a recomendação de cursos, de início, limitar-se-á a projetos oriundos de instituições que já possuam curso(s) de pós-graduação com conceito A ou B"; a de $1998^{2}$ é mais flexível: "as instituições... [que] revelem claramente qualificação científica, tecnológica e/ ou artística presumem-se qualificadas". Já nos Parâmetros para Avaliação de $1999^{3}$, a legislação parece indicar uma direção, ao dizer que estão aptas a oferecer MP "preferencialmente programas credenciados pela Capes e que desenvolvam atividades de extensão ou prestação de serviços no campo".

Sobre a recomendação do curso pela Capes, observa-se que os critérios explicitados na Portaria de $1995^{1}$ - instituições com programas stricto sensu com conceitos A ou B e instituições de "alta qualificação", desaparecem na Portaria de $1998^{2}$. Nela se explicita que qualquer instituição, independente do conceito na avaliação Capes, poderia oferecer MP. No entanto, nos Parâmetros para Avaliação de $1999^{3}$, programas que desenvolvam atividades de extensão e de prestação de 
serviços no campo têm preferência para o credenciamento do MP. Essas deliberações poderiam caracterizar o viés profissional do MP em contraposição ao MA, porque pressuporia uma maior proximidade com o mundo do trabalho.

Em relação às instituições que se habilitariam a encaminhar propostas de cursos de MP, a primeira Portaria diz que todas as instituições são presumivelmente qualificadas para oferecer cursos de MP. Já a Portaria $2009^{5}$ diz que "poderão ser propostos por universidades, instituições de ensino e centro de pesquisas [...] demonstrando experiência na prática de pesquisa aplicada".

A imprecisão destacada acima pode tornarse uma evidência. No primeiro caso, o uso do verbo presumir, supor antecipadamente, indica possibilidade; do mesmo modo, a segunda Portaria, ao usar o verbo "poder". Em ambos os casos, a legislação deixa a questão em aberto para que seja matéria de deliberação posterior.

Nas propostas de cursos, na descrição das características dos docentes, é recorrente a semelhança dos marcadores linguísticos utilizados na legislação: "titulação acadêmica de doutorado ou equivalente e profissionais com experiência reconhecida na área" (P1); "titulação acadêmica e currículo compatíveis (Doutorado) e outros profissionais" (P2); "professores doutores e profissionais de qualificação profissional reconhecida" (P10). Essas semelhanças poderiam levar o leitor a compreender essas características como um discurso unitário (no sentido forte do termo) ou como um processo uniforme. Isso em parte, responderia pelo mimetismo das propostas ao texto da legislação, que se mostra contraditório em relação ao processo avaliativo e omisso na definição de critérios sobre a participação dos profissionais ditos "não acadêmicos".

Essa ambiguidade seria reforçada pelo uso de marcadores linguísticos que ora traduzem certeza ora possibilidade, como por exemplo, "e" indicando adição de termos, "poder", que enuncia a ideia de faculdade, possibilidade ou autorização, diferentemente de "dever", que sugere obrigatoriedade. Trata-se da construção de noções diferenciadas sobre o mesmo aspecto, como nas frases: "composto por profissionais com titulação acadêmica de doutorado ou equivalente e profissionais com experiência reconhecida na área" (P1); "docente doutor $e$ docentes indicados pela Secretaria Estadual de Saúde podem eventualmente participar como convidados" (P13); "doutores na área de Saúde Pública, outros professores deverão ser convidados para docência de tópicos específicos" (P5 e P9) [grifos nossos].
A ambiguidade é recorrente nos critérios de credenciamento de docentes, o que pode sugerir que a legislação não regularia de modo satisfatório sobre essa matéria, mas também porque na avaliação do MP pesariam os critérios utilizados no MA, dentre eles a produtividade acadêmica.

$\mathrm{Na}$ instituição-caso, a norma que prevê a predominância de doutores nos cursos, poderia ser explicada pelo fato dela possuir em torno de $80 \%$ de profissionais com essa qualificação. Outro elemento que poderia corroborar essa afirmação é o texto do documento de $2002^{4}$ sugerir "ser constituído predominantemente por doutores (no mínimo o dobro dos especialistas sem doutoramento)".

Quanto aos critérios de credenciamento externo do curso, as propostas não fazem referências explícitas, considerando que quando os cursos de MP começaram a ser ofertados, em 2002, o Programa de Pós-graduação da instituição-caso enquadrava-se no critério de "programa com conceito A ou B". As propostas somente eram submetidas a um processo interno de aprovação, que incluía parecer técnico dado por especialista na área.

\section{Trabalho de conclusão de curso (TCC)}

Predomina no texto da legislação a indicação de que o trabalho final seja um produto consistente, aparentemente mais diversificado do que o do MA, o que seria coerente com a proposta do MP: "dissertação, projeto, análise de casos, performance, produção artística, desenvolvimento de instrumentos, equipamentos, protótipos" ${ }^{2}$. Entretanto, somente no documento de $2002^{4}$ se explicita que o TCC deve ser avaliado por banca qualificada, com integrantes externos à instituição, como é tradição no MA. Nesse documento também se define quem está credenciado a orientar, e os aspectos acadêmicos em detrimento dos profissionais são predominantes. Já na Portaria de $2009^{5}$, o leque de formatos em que os TCC podem ser apresentados se amplia. Chama a atenção haver na Portaria de $1998^{2}$ uma preocupação quanto à qualidade dos novos formatos, indicada pelas expressões "domínio do objeto de estudo" e "capacidade de expressar lucidamente sobre eles"; no entanto, na Portaria de $2009^{5}$ essa referência desaparece.

Nas propostas da instituição-caso, predomina o formato da dissertação tradicional, embora em quatro delas (P7, P14, P15, P18) o desenvolvimento de um produto final diversificado, acompanhe a legislação: "O produto deverá contem- 
plar módulos ou planos de monitoramento e avaliação" (P7); "deve contemplar o desenvolvimento de tecnologia, diagnóstico ou solução orientada a problemas definidos no início da formação" (P14); "estudo sob a forma de dissertação, projeto, análise de casos, desenvolvimento de instrumentos, equipamentos, protótipos, entre outros, de acordo com a natureza do tema" (P18).

Para esse resultado pode-se formular três hipóteses: 1) os docentes não dominariam outra que não essa forma de apresentação de trabalho final; 2) como o MA da instituição preconiza a elaboração de produtos dessa natureza, as propostas de MP somente repetiram o que estava estabelecido;3) e ou a ideia ainda largamente cristalizada de que o MP, para ter o mesmo valor que o MA, deve exigir o mesmo produto.

Diferente do que se pensa ordinariamente, a forma não é universal a ponto de acomodar o conteúdo. Uma dissertação tem exigências formais que não estão presentes em um projeto de lei, protótipo, performance, etc.; exigências essas capazes de alterar inclusive o próprio conteúdo. Não se pode partir do princípio de que todas as demandas de pesquisa dos alunos de MP sejam passíveis de se acomodarem em uma dissertação. Tratar-se-ia de um formalismo ditado pela preeminência acadêmica, que se observado cuidadosamente, revelaria também outra face dessa hegemonia em relação a outras formas de produção e apresentação de conhecimento científico.

\section{Avaliação externa}

Até 2009 os critérios do sistema de avaliação da Capes para o MP eram semelhantes aos do MA. Nos documentos analisados não é explícito se sua utilização guarda semelhanças com o MA, embora a Portaria de $1998^{2}$ determinasse que: "Os programas de mestrado avaliados de acordo com os padrões tradicionais poderão solicitar o enquadramento como 'Mestrado profissionalizante' mediante demonstração de que suas respectivas propostas e orientação estejam voltadas para esta modalidade de formação profissional, ou aprovação, pela Capes, da reformulação de suas propostas".

Considerando que não é a instituição-caso a credenciar o curso, identifica-se nas propostas um entendimento diferenciado para o termo "avaliação". Predominam referências à avaliação da aprendizagem dos alunos; seis delas "preveem avaliação docente, coordenadores, orientadores e infraestrutura do curso e avaliação discente dos trabalhos das disciplinas" (P1) para verificação da aprendizagem; no entanto, nenhuma proposta faz referência a um sistema de acompanhamento de egressos o qual poderia auxiliar no aperfeiçoamento do programa curricular.

\section{Fontes de financiamento}

A legislação ora diz que a Capes dará apoio ao MP tal qual ao MA, ora é omissa. A Portaria de $1995^{1}$ declara que o MP tem vocação para o autofinanciamento, discurso que se repete na Portaria de $1998^{2}$. Nos Parâmetros para Avaliação de $1999^{3}$, entretanto, a redação é ambígua: "a Capes, em princípio não financia cursos de MP. Mediante ação indutora poderá vir a apoiar iniciativas voltadas para o desempenho de funções básicas do Estado". Isso poderia significar a possibilidade de o financiamento vir a ocorrer, no entanto sob circunstâncias pouco claras. Diferentemente, por exemplo, do texto do documento de $2002^{4}$ que omite qualquer participação da Capes nesse sentido: "A instituição promotora deve formalizar o compromisso com o oferecimento, manutenção e conclusão do curso". Se a Portaria de $1998^{2}$ destaca que o MP tem vocação para o autofinanciamento, nas de $2009^{5,6} \mathrm{o}$ assunto não aparece. As propostas da instituiçãocaso não fazem referência a este assunto, porque estabeleceu, de acordo com a legislação, mecanismos de negociação com as instituições demandantes para o financiamento dos cursos. O Quadro 3 sintetiza os resultados acima discutidos.

\section{Considerações finais}

Ao realizar um estudo com propostas de cursos de MP em uma única instituição, sem o compromisso de verificar sua correspondência com o efetivamente realizado, poderia levar a um exercício interpretativo sobre o devir, mais do que sobre o havido, o que caracterizaria um limite do estudo. Ao contrário, entende-se que essas propostas podem ser consideradas documentos sobre os quais se acordam e se ajustam as expectativas das instituições demandantes com as características do que a instituição formadora lhes oferece, e que isso poderia estar representado nas instituições na área da saúde pública. Assim, assumiu-se no presente estudo que o conjunto das propostas expressariam suficientemente as intencionalidades e, sobretudo, a visão das instituições formadoras sobre essa modalidade stricto sensu e cuja identidade ainda parece pouco determinada. 
Quadro 3. Quadro-síntese dos resultados do Estudo.

\begin{tabular}{|c|c|c|}
\hline Categorias & Legislação & Propostas de curso da instituição-caso \\
\hline $\begin{array}{l}\text { Relação } \\
\text { academia- } \\
\text { contexto } \\
\text { profissional }\end{array}$ & $\begin{array}{l}\text { Incentiva o intercâmbio da academia } \\
\text { com as empresas e instituições } \\
\text { interessadas no MP. }\end{array}$ & $\begin{array}{l}\text { Articulação ainda é genérica ou inexistente } \\
\text { pela ausência de diagnósticos que } \\
\text { justifiquem a necessidade de cursos na } \\
\text { modalidade MP. Conforme a estratégia } \\
\text { prevista na legislação de promover essa } \\
\text { articulação, algumas propostas previram a } \\
\text { realização de oficinas de trabalho com a } \\
\text { instituição demandante. }\end{array}$ \\
\hline $\begin{array}{l}\text { Estrutura } \\
\text { curricular }\end{array}$ & $\begin{array}{l}\text { A legislação destaca que o currículo } \\
\text { deve ser específico, voltado para } \\
\text { aplicabilidade prática, ter flexibilidade } \\
\text { operacional e organização do } \\
\text { conhecimento técnico-científico. }\end{array}$ & $\begin{array}{l}\text { O currículo é organizado por módulos ou } \\
\text { unidades de aprendizagem, de caráter } \\
\text { interdisciplinar, com a realização de } \\
\text { estágios. A relação teoria-prática aparece de } \\
\text { modo recorrente nas propostas de curso. } \\
\text { Contudo, essa variedade de modelos } \\
\text { pedagógicos não apresenta indicativos claros } \\
\text { de suas razões, e não há detalhamento de } \\
\text { como esses processos se realizarão. }\end{array}$ \\
\hline $\begin{array}{l}\text { Credenciamento } \\
\text { docente e do } \\
\text { curso }\end{array}$ & $\begin{array}{l}\text { Texto vago quanto à participação de } \\
\text { doutores e de profissionais. Quanto ao } \\
\text { credenciamento do curso o texto da } \\
\text { legislação foi se tornando flexível ao } \\
\text { longo dos anos, com as sucessivas } \\
\text { portarias. }\end{array}$ & $\begin{array}{l}\text { A ambiguidade da legislação é reproduzida } \\
\text { nas propostas de cursos, no que diz respeito } \\
\text { à presença de doutores e de profissionais no } \\
\text { curso. }\end{array}$ \\
\hline $\begin{array}{l}\text { Trabalho de } \\
\text { conclusão de } \\
\text { curso }\end{array}$ & $\begin{array}{l}\text { Produto final com formato } \\
\text { diversificado. }\end{array}$ & $\begin{array}{l}\text { Predomínio do formato de dissertação } \\
\text { como produto final. }\end{array}$ \\
\hline $\begin{array}{l}\text { Avaliação } \\
\text { Externa }\end{array}$ & $\begin{array}{l}\text { Não há clareza quanto à semelhança } \\
\text { que o MP guarda com o MA no } \\
\text { processo de avaliação externa. }\end{array}$ & $\begin{array}{l}\text { Predomínio da avaliação da aprendizagem } \\
\text { dos alunos. Algumas propostas preveem } \\
\text { avaliação de cursos, de professores e } \\
\text { coordenação. Nenhuma faz referência à } \\
\text { avaliação de egressos. }\end{array}$ \\
\hline $\begin{array}{l}\text { Fontes de } \\
\text { financiamento }\end{array}$ & $\begin{array}{l}\text { A legislação ora define o tipo de apoio } \\
\text { financeiro que será oferecido pela } \\
\text { Capes, ora é omissa nesta matéria. }\end{array}$ & $\begin{array}{l}\text { Não há qualquer referência a este assunto } \\
\text { nas propostas de curso. }\end{array}$ \\
\hline
\end{tabular}

A análise dos discursos sobre o MP presentes nas propostas dos cursos, vis-à-vis o marco regulatório da Capes, apontou ambiguidades de diversas naturezas. Elas foram elaboradas com a mesma linguagem da legislação, e a partir da tradição consolidada da modalidade acadêmica. Pode-se perceber que, a partir da Portaria de $2009^{5}$, essas ambiguidades diminuem; mesmo assim ainda seria necessário refletir sobre como as instituições formadoras entendem o MP ao construir suas propostas.
Outras áreas do conhecimento fizeram reflexões teóricas sobre algumas dimensões tratadas neste artigo. Em uma delas, administração, o autor $^{16}$, ao ponderar sobre o financiamento dos cursos, concluiu que:

...as características atuais dos Mestrados Profissionais poderia revelar que a exigência de financiamento independente das fontes governamentais de recursos pode representar um filtro pelo qual só passem profissionais já absorvidos por empresas ou por instituições públicas (ou porque essas empre- 
sas ou instituições estão financiando o projeto, ou porque têm renda que permite assumir essa despesa, muitas vezes alta, com a formação complementar). Interessados que não estejam em uma dessas condições terão dificuldade de se engajar em Mestrados Profissionais.

Ainda permanecem duas interrogações: como a legislação educacional se efetiva nas práticas sociais de formação escolar e qual o papel da lei na organização dos processos pedagógicos? Em que medida a legislação determina os projetos de formação e de que modo estes oferecem argumentos teóricos e práticos de apoio ao argumento legal? São questões que merecem ser estudadas em investigações futuras para se compreender como as instituições formadoras definem a identidade do MP.

\section{Colaboradores}

GBS trabalhou em todas as etapas do estudo e da produção do artigo e VAH trabalhou na concepção do estudo, na análise dos dados e na redação do artigo.

\section{Agradecimentos}

Agradecemos à Direção da instituição-caso pelo apoio à realização desta pesquisa. 


\section{Referências}

1. Capes. Portaria n ${ }^{\circ}$ 47, de 17 de outubro de 1995 Determina a implantação na Capes de procedimentos apropriados à recomendação, acompanhamento e avaliação de cursos de mestrado dirigidos à formação profissional. RBPG 1995; 2(4):147-148.

2. Brasil. Portaria $\mathrm{n}^{\circ} 80$ de 16 de dezembro de 1998. Dispõe sobre o reconhecimento dos mestrados profissionais e dá outras providências. Diário Oficial da União 1999; 11 jan.

3. Parâmetros para análise de projetos de Mestrado Profissionalizante. Infocapes 1999; 7(4):54-58.

4. Oller C, Sotero A, Moreira MA, Fischer T, Nicola JH. Parâmetros para Avaliação do Mestrado Profissional. RBPG 2005; 4(2):151-155.

5. Brasil. Portaria Normativa $n^{\circ} 7$, de 22 de junho 2009. Dispõe sobre o mestrado profissional no âmbito da Fundação Coordenação de Aperfeiçoamento de Pessoal de Nível Superior. Diário Oficial da União 2009; 23 jun

6. Brasil. Portaria Normativa $\mathrm{n}^{\circ} 17$, de 28 de dezembro 2009. Dispõe sobre o mestrado profissional no âmbito da Fundação Coordenação de Aperfeiçoamento de Pessoal de Nível Superior - Capes. Diário Oficial da União 2009; 29 dez.

7. Hortale VA. Mestrado Profissionalizante em Saúde Pública: Um Olhar para as Experiências Internacionais. In: Leal MC, Freitas CM, organizadores. $\mathrm{Ce}$ nários possíveis: experiências e desafios do mestrado profissional na saúde coletiva. Rio de Janeiro: Fiocruz; 2006. p. 65-99.

8. Negret F. A identidade e a importância dos mestrados profissionais no Brasil e algumas considerações para a sua avaliação. RBPG 2008; 5(10):217-225

9. Freitas CM, Rivera FJU, Artmann E, Santos RV. O Mestrado Profissional nos cenários Futuros da Escola Nacional de Saúde Pública, Fundação Oswaldo Cruz. RBPG 2006; 3(5):129-149.
10. Hortale VA, Moreira COF, Koifman L. Avaliação da qualidade da formação: contribuição à discussão na área da Saúde Coletiva. Cien Saude Colet 2004; 9(4):997-1002.

11. Hortale VA, Moreira COF. Auto-avaliação nos programas de pós-graduação na área da saúde coletiva: características e limitações. Cien Saude Colet 2008; 13(1):223-233.

12. Leal MC, Freitas CM, organizadores. Cenários Possiveis: experiências e desafios do mestrado profissional na saúde coletiva. Rio de Janeiro: Editora Fiocruz; 2006.

13. Santos GB, Hortale VA, Arouca R. Mestrado Profissional em Saúde Pública: caminhos e identidade. Rio de Janeiro: Fiocruz; 2012.

14. Gill R. Análise do Discurso. In: Bauer MW, Glaskell G, organizadores. Pesquisa qualitativa com imagem, texto e som: um manual prático. Petrópolis: Vozes; 2002. p. 240-270.

15. Brandão MHN. Introdução à análise de discurso. $2^{\circ}$ ed. rev. Campinas: Editora da Unicamp; 2004. 16. Menandro PRM. Réplica 2 - Mestrado Profissional, você sabe com quem está falando? Rev. adm. contemp. 2010; 14(2):376-371.

Artigo apresentado em 10/04/2013

Aprovado em 28/05/2013

Versão final apresentada em 10/06/2013 
